\title{
"Com uma autoanálise, rápida e franca, eu diria que não estou preparado para estas novas competências": um estudo sobre a percepção dos jovens em relação às perspectivas na transição da escola para o trabalho
}

\begin{abstract}
Resumo:
Este artigo apresenta resultados de uma pesquisa cujo objetivo foi identificar a percepção dos jovens em relação às perspectivas na transição da escola para o trabalho no que se refere a estar preparado(a) para as demandas e competências digitais do mundo do trabalho. A afirmação que a pandemia mundial da covid-19 expôs algumas inseguranças da vida cotidiana, por exemplo, as incertezas relacionadas à saúde, ao trabalho, a educação, as tecnologias, entre outras e, que também destacou a importância das tecnologias digitais e da conectividade principalmente em relação ao acesso aos serviços remotamente, incluindo educação e trabalho, revela-se o fio condutor para a reflexão deste estudo. Neste artigo utilizou-se a pesquisa descritiva, qualitativa, com survey realizado no mês de maio de 2020, de forma on-line com 30 jovens na cidade de Novo Hamburgo (RS). O referencial teórico descreve questões sobre juventudes, conexão e inclusão digital, conta com os autores Bauman, Castells, Feixa, Reguillo Cruz, Van Dijck, Winocur, entre outros. Os resultados apontam que os jovens possuem receios em relação ao seu futuro profissional e que não se consideram plenamente preparados para o mercado de trabalho e por isso, compreendem uma necessidade de qualificação constante em relação ao futuro do trabalho.
\end{abstract}

\section{Palavras-Chave:}

Juventudes. Brecha Digital. Inclusão Digital. Mundo do Trabalho.

\section{"With a quick and frank self-analysis, I would say that I am not prepared for these new skills": a study on the perception of young people in relation to the perspectives on the transition from school to work}

\footnotetext{
Abstract: This article presents results of a research whose objective was to identify the perception of young people in relation to the perspectives in the transition from school to work in terms of being

1 Doutora em Diversidade Cultural e Inclusão Social, Professora na Faculdade IENH. E-mail: viana.luciane.lu@gmail.com. ORCID iD: http://orcid.org/0000-0002-9577-728X.

2 Doutor em Estudos Estratégicos Internacionais, Doutor em Diversidade Cultural e Inclusão Social, Professor na Universidade Feevale. E-mail: viana-andre@outlook.com. ORCID iD: https://orcid.org/0000-0001-8686-1204.
} 
“Com uma autoanálise, rápida e franca, eu diria que não estou preparado para estas novas competências"...

prepared for the demands and digital skills of the world of work. The statement that the global pandemic of covid-19 exposed some insecurities in everyday life, for example, uncertainties related to health, work, education, technologies, among others, and that also highlighted the importance of digital technologies and connectivity mainly in relation to accessing services remotely, including education and work, the guiding thread for the reflection of this study is revealed. In this article, descriptive, qualitative research was used, with a survey online, carried out in May 2020, with 30 young people in the city of Novo Hamburgo (RS). The theoretical framework describes issues about youth, connection and digital inclusion, with the authors Bauman, Castells, Feixa, Reguillo Cruz, Van Dijck, Winocur, among others. The results show that young people are afraid of their professional future and that they do not consider themselves fully prepared for the job market and therefore understand a need for constant qualification in relation to the future of work.

Keywords: Youth. Digital Divide. Digital Inclusion. Work.

\section{"Con un autoanálisis rápido y franco, diría que no estoy preparado para estas nuevas habilidades": un estudio sobre la percepción de los jóvenes en relación a las perspectivas sobre la transición de la escuela al trabajo}

Resumen: Este artículo presenta resultados de una investigación cuyo objetivo fue identificar la percepción de los jóvenes en relación a las perspectivas en la transición de la escuela al trabajo en términos de preparación para las demandas y competencias digitales del mundo laboral. El comunicado de que la pandemia global de covid-19 expuso algunas inseguridades en la vida cotidiana, por ejemplo, incertidumbres relacionadas con la salud, el trabajo, la educación, las tecnologías, entre otras, y que también destacó la importancia de las tecnologías digitales y la conectividad. principalmente en relación al acceso a los servicios de forma remota, incluida la educación y el trabajo, se revela el hilo conductor de la reflexión de este estudio. En este artículo se utilizó una investigación descriptiva, cualitativa, con una encuesta en línea, realizada en mayo de 2020, con 30 jóvenes de la ciudad de Novo Hamburgo (RS). El marco teórico describe temas sobre juventud, conexión e inclusión digital, con los autores Bauman, Castells, Feixa, Reguillo Cruz, Van Dijck, Winocur, entre otros. Los resultados muestran que los jóvenes tienen miedo de su futuro profesional y que no se consideran plenamente preparados para el mercado laboral y, por tanto, comprenden la necesidad de una cualificación constante en relación con el futuro del trabajo.

Palabras clave: Jóvenes. Brecha Digital. Inclusión Digital. Trabajo.

\section{Introdução}

Observa-se que a juventude contemporânea vive cada vez mais mediada pela tecnologia digital, sendo que o crescente número de smartphones tende a modificar as práticas da vida cotidiana e os processos no mercado de trabalho. Logo, envolver professores e estudantes no desenvolvimento e orientação sobre as habilidades e conhecimentos frente às potencialidades oferecidas pela cultura digital, auxiliando na transição da escola para o trabalho, configura-se como ponto fundamental, haja vista que as competências digitais para o mundo do trabalho se constroem de modo processual.

Segundo a GSMA (2020) o consumo de telefones celulares teve um crescimento de 205\% nos últimos dez anos (2008 a 2018). Mundialmente, cerca de 3,2 bilhões de pessoas estão conectadas, sendo que 2,4 bilhões por meio de um aparelho celular (soma da quantidade de celulares e smartphones). Em 2019 foram vendidos 87 smartphones por minuto no Brasil, sendo que se chegou a 226 milhões de aparelhos, com 107 acessos por cem habitantes (TELECO, 2020). 
No entanto, atualmente, 4 bilhões de pessoas ainda estão desconectadas ou com acesso limitado à internet, ou seja, uma parcela da população mundial não pode usufruir efetivamente dos benefícios e oportunidades do mundo conectado, o que constitui uma brecha digital. Segundo a ONU (2011, p. 17, tradução nossa) "o termo 'brecha digital' refere-se à lacuna entre pessoas com acesso efetivo a tecnologias digitais e de informação, em particular a Internet, e aquelas com acesso muito limitado ou sem acesso algum"1.

Para Castells et al. (2006) a brecha digital consiste em uma divisão digital com diferenças entre países desenvolvidos e em desenvolvimento, zona rural e urbana, acesso a conexão de internet e móvel, classe social, entre outros fatores. Conforme a GSMA (2020) as principais causas da brecha digital são a ausência de conteúdo local relevante, a acessibilidade reduzida devido aos altos custos dos dispositivos e dos valores de redes móveis, falta de infraestrutura na rede e a falta de habilidades e alfabetização digitais suficientes, detalhados na próxima seção.

Assim, este artigo tem como objetivo identificar a percepção dos jovens em relação às perspectivas na transição da escola para o trabalho no que se refere a estar preparado(a) para as demandas e competências digitais do mundo do trabalho. A partir do que já fora exposto, apresenta-se a seguinte pergunta de pesquisa: Os jovens acreditam estar preparados(as) para as demandas e competências digitais do mundo do trabalho?

Vale ressaltar que, com o objeto de pesquisa da presente investigação dissertando em torno do estudo sobre a inclusão digital na juventude contemporânea relacionada à escola e trabalho, houve a necessidade de delimitação e de um recorte, para tanto, se utiliza neste estudo o parâmetro biológico (indivíduos de 15 a 29 anos) para escolha dos jovens pesquisados, ou seja, seguindo a definição adotada pela Unesco em sua pesquisa Juventude, juventudes: o que une e o que separa?, realizada em 2004 (ABRAMOVAY; CASTRO, 2006).

Contudo, entende-se que a juventude contemporânea é uma mescla de contradições, complexidade e expressões culturais e, que conforme Sarlo (1997, p. 36) "a juventude não é uma idade, e sim uma estética da vida cotidiana". Também se utilizando artigo o termo "juventudes", como base os estudos de Bauman (2013), Feixa (1999, 2004), Garbin et al. (2006), Pais (1990), Reguillo Cruz (2010), Rocha e Pereira (2009), Sarlo (1997), Schmidt (2007), Velho (2006), entre outros, pois essa categoria assume que a juventudes passam por uma diversidade de experiências sociais e culturais, pelas quais operam suas identidades a partir de interações com o outro e com suas subjetividades.

No percurso metodológico utilizou-se uma pesquisa descritiva, qualitativa, dividida em dois procedimentos: bibliográfica e survey (FREITAS; PRODANOV, 2013). A pesquisa bibliográfica buscou discutir questões sobre juventudes, conexão e inclusão digital e contou com os autores Bauman, Castells, Feixa, Reguillo Cruz, Van Dijck, Winocur, entre outros.

O levantamento (survey) foi realizado no mês de maio de 2020, de forma on-line com 30 jovens na cidade de Novo Hamburgo (RS). O questionário possuía uma questão fechada e uma aberta. A questão fechada tinha como objetivo caracterizar o respondente em relação a idade. Sendo utilizado como base para a escala de idades as definições adotadas pela UNESCO (ABRAMOVAY; CASTRO, 2006) e pelo Estatuto da Juventude Brasileiro (BRASIL, 2013), que define como jovens as pessoas com idade de 15 a 29 anos, e o Estatuto do Idoso (BRASIL, 2003), que assegura direitos diferenciais às pessoas com idade igual ou superior a 60 anos, portanto, de 30 a 59 anos são intitulados adultos e menores de 15 anos como crianças.

$\mathrm{Na}$ questão aberta foi habilitado respostas longas em um ou mais parágrafos. A pergunta indagava: "Você se acha preparado(a) para as demandas e competências digitais do mundo do trabalho? Por quê?". A coleta dos dados ocorreu utilizando o meio eletrônico e a ferramenta de formulários do Google como método de campo, sendo escolhida a mídia social Facebook e grupos

1 No original: "The term "digital divide" refers to the gap between people with effective access to digital and information technologies, in particular the Internet, and those with very limited or no access at all." 
“Com uma autoanálise, rápida e franca, eu diria que não estou preparado para estas novas competências”...

de WhatsApp para divulgação. Foi definida a amostragem não-probabilística por conveniência, sendo determinado como fator de amostra o tempo de um mês de disponibilidade da pesquisa (FREITAS; PRODANOV, 2013). Os respondentes da pesquisa são pertencentes às "camadas médias urbanas" (VELHO, 1988). Neste período, 30 jovens responderam à pesquisa, não havendo participantes de outras faixas etárias.

Por fim, optou-se pela análise de conteúdo, segundo Bardin (2004), sendo obedecidas as seguintes fases: a) pré-análise com preparação do material com a escolha dos relatos para compor o artigo; b) exploração do material, com definição das categorias: necessidades e competências; c) tratamento dos resultados, inferência e interpretação. Este artigo está dividido em três seções, sendo a primeira essa introdução, a segunda o referencial teórico seguido pelos resultados, por fim, a terceira seção apresenta as considerações finais.

\section{Juventudes e inclusão digital}

A pandemia mundial da covid- $19^{2}$ expôs algumas inseguranças da vida cotidiana, por exemplo, as incertezas relacionadas à saúde, ao trabalho, à educação, às tecnologias, entre outras. Também destacou a importância das tecnologias digitais e da conectividade principalmente em relação ao acesso aos serviços remotamente, incluindo educação e trabalho. Bauman e Raud (2018, p. 98) explicam que

nós - cada um de nós - vivemos agora, de modo intermitente, mas muitas vezes simultâneo, em dois universos absolutamente distintos: on-line e off-line. Este último é muitas vezes chamado de 'mundo real', embora determinar se esse rótulo é mais adequado que o primeiro venha se tornando mais discutível cada dia que passa.

Conforme GSMA (2021, tradução nossa) “a indústria móvel na América Latina enfrentou o desafio de sustentar a atividade social e econômica na região durante a pandemia, apesar do crescimento sem precedentes no tráfego de dados. Em média, as operadoras relataram um aumento de $25 \%$ no tráfego de dados móveis durante o bloqueio"3. O setor de telefonia móvel é um dos pilares da economia mundial. Em 2019, conforme GSMA Latin America (2020), as tecnologias e serviços móveis geraram 7\% do PIB na América Latina e Caribe, o setor contribuiu com US\$ 421 bilhões em valor econômico (Figura 1).

2 A covid-19 é uma doença causada pelo coronavírus denominado SARS-CoV-2, que apresenta um espectro clínico variando de infecções assintomáticas a quadros graves. A partir de dezembro de 2019 houve a primeira confirmação de transmissão (SARS-CoV-2) identificado em Wuhan na China, sendo em seguida transmitido mundialmente (MINISTÉRIO DA SAÚDE, 2021).

3 No original: "La industria móvil en América Latina ha hecho frente al desafío de sostener la actividad social y económica de la región durante la pandemia, a pesar de un crecimiento sin precedentes del tráfico de datos. En promedio, los operadores informaron un aumento del $25 \%$ en el tráfico de datos móviles durante el aislamiento." 
Figura 1 - Contribuição do ecossistema móvel no PIB da América Latina e Caribe em 2019

\section{Mobile contributed \$421 billion to Latin America's economy in 2019}

\$ billion, \% of GDP 2019
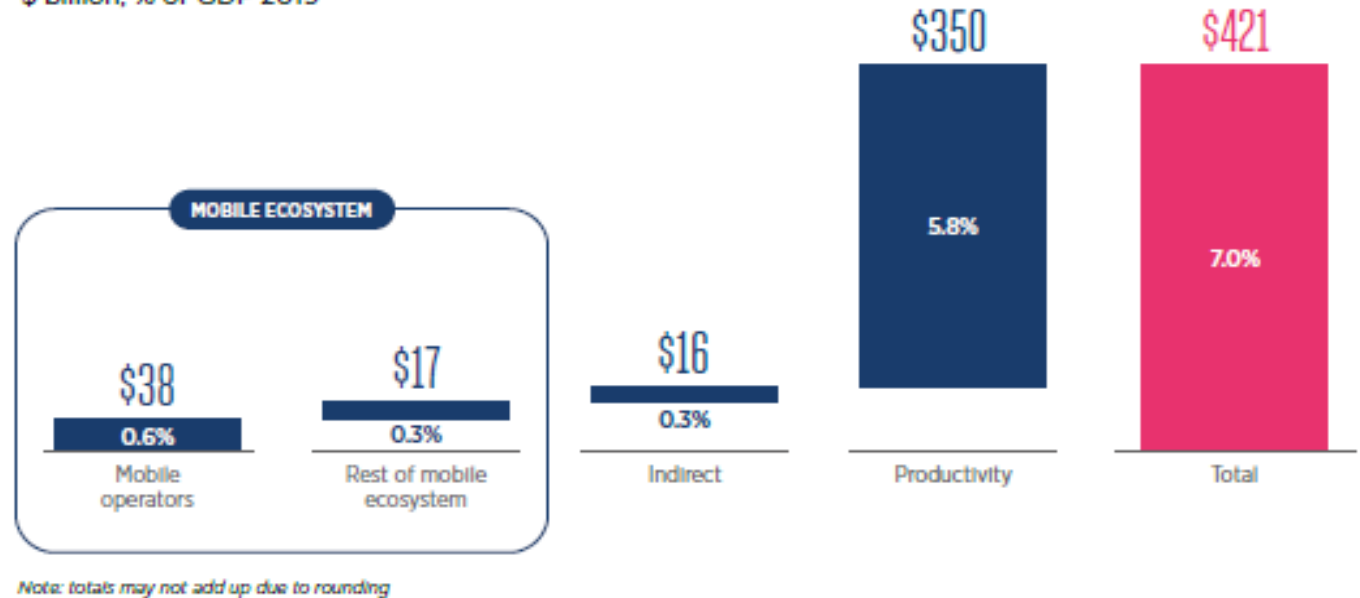

Fonte: GSMA LATIN AMERICA (2020, p. 30).

O ecossistema móvel respondeu por 623.000 empregos contratados diretamente em 2019 na América Latina e Caribe e 1,4 milhão de empregos decorrentes da atividade econômica gerada por todo o ecossistema (Figura 2).

Figura 2 - Impacto do emprego América Latina e Caribe em 2019

\section{The mobile ecosystem directly employs 620,000 people in Latin America, and supports another $\mathbf{8 1 0 , 0 0 0}$ jobs indirectly in other parts of the economy}

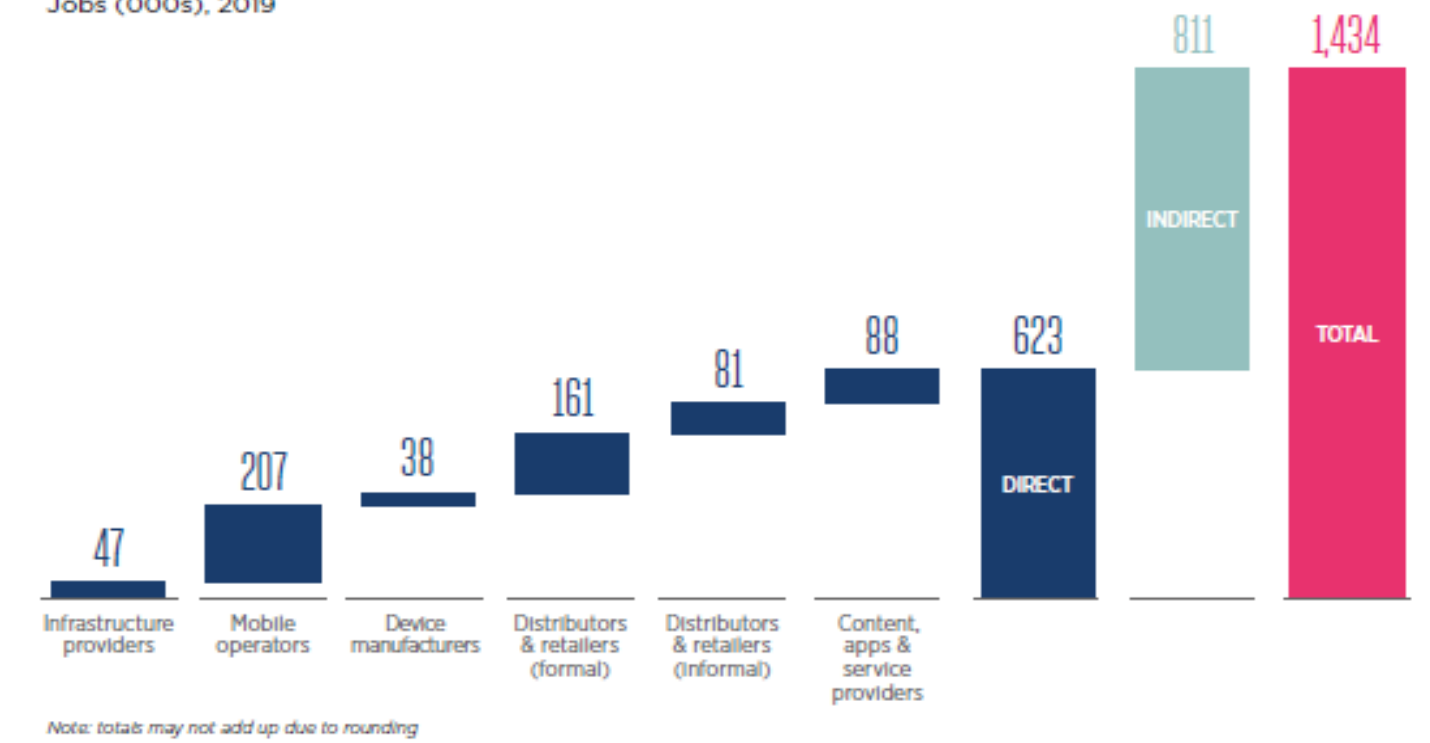

Fonte: GSMA LATIN AMERICA (2020, p. 28).

Além da contribuição no PIB e empregos do ecossistema mobile, entende-se que a expansão da conectividade global e da internet móvel podem proporcionar benefícios socioculturais e econômicos, entre eles a inclusão digital.

A conectividade através das telecomunicações é um pré-requisito essencial para o desenvolvimento em nosso mundo globalizado. A brecha da conectividade é um dos maiores obstáculos para os países em desenvolvimento e das regiões pobres para se engajarem na dinâmica 
economia global e com as redes de comunicação global que oferecem acesso à informação, educação e serviços ${ }^{4}$. (CASTELLS et al., 2006, p. 374, tradução nossa).

Algumas vezes, a premissa básica da inclusão digital (via senso comum) incide no acesso ao computador e aos conhecimentos básicos para utilizá-lo. No entanto, a inclusão digital abrange uma discussão mais ampla, contemplando questões de direito de comunicação na esfera on-line (WINOCUR, 2007). Para Sorj (2003) a exclusão digital está vinculada às desigualdades de infraestrutura, de acesso a bons dispositivos, treinamento de uso aos dispositivos e internet (alfabetização digital), capacitação intelectual e inserção social do jovem e produção e uso de conteúdo específico adequados às necessidades, principalmente no idioma local.

Tais dimensões são também citadas na pesquisa realizada pela GSMA Latin America (2020) na qual foram mencionados quatro desafios chaves para a expansão da inclusão digital: aumento de cobertura de rede (infraestrutura), acessibilidade, aumento de habilidades digitais (alfabetização) e de conteúdo local relevante. Os percentuais das principais barreiras à inclusão digital estão apresentados na Figura 3.

Figura 3 - Principais barreiras à inclusão digital América Latina e Caribe 2016-2019

\section{According to the GSMA's Mobile Connectivity Index, infrastructure has improved significantly, reflecting operators' investment in 4G networks, but affordability remains low} GSMA Mobile Connectivity Index scores
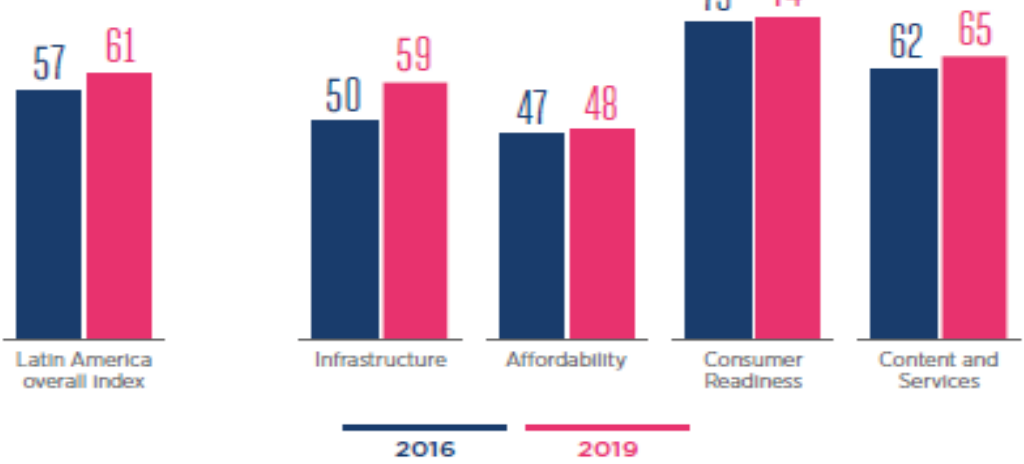

Readiness

Fonte: GSMA LATIN AMERICA (2020, p. 28)

$\mathrm{Na}$ Figura 3 pode-se verificar que as quatro barreiras tiveram melhora nos seus índices entre os anos de 2016 e 2019, apesar disso, todos ainda estão abaixo de $80 \%$. Sendo que, a acessibilidade é o menor, segundo a GSMA (2021) este índice deve-se especialmente em função dos altos impostos dos serviços móveis. Neste artigo, optou-se por enfatizar o fator alfabetização digital, pois conforme o relatório da GSMA Latin America (2020) são poucos os países da região que contam com programas escolares formais e infraestrutura de TICs (Tecnologias de Informação e Comunicação), bem como professores suficientemente qualificados para ensinar sobre as TIC.

Este problema se agrava ainda mais quando é considerado a oferta limitada de conteúdo relevante no idioma local. Pois, de acordo com a GSMA (2021), menos de 30\% do conteúdo da internet na América Latina e Caribe é consumido no idioma local, o que dificulta que os jovens possam adquirir competências digitais importantes para uma total inserção digital. Para Gentile e Bencini (2000) "competência é a faculdade de mobilizar um conjunto de recursos cognitivos (saberes, capacidades, informações etc) para solucionar com pertinência e eficácia uma série de situações". 
Já a competência digital, segundo a Comissão das Comunidades Europeias (COM, 2005) envolve a utilização crítica e com segurança das TICs para uso em momentos de lazer, trabalho, informação e comunicação. "É sustentada pelas competências em TIC: o uso do computador para recuperar, avaliar, armazenar, produzir, apresentar e trocar informação e para comunicar e participar em redes de cooperação via Internet" (COM, 2005). Para a Unesco (2009) as Competência em TIC para professores e alunos devem contemplar a alfabetização em tecnologia, o aprofundamento do conhecimento e a criação do conhecimento.

Conforme a GSMA (2017) a alfabetização móvel apresenta quatro estágios: realizar e receber chamadas de voz, usar câmera, calendário, mensagens de texto e outros recursos, habilidade para pesquisar via internet e com aplicativos, criar e consumir conteúdos on-line e em dispositivos (Figura 4).

Figura 4 - Estágios da alfabetização mobile

\section{Explaining mobile internet literacy}

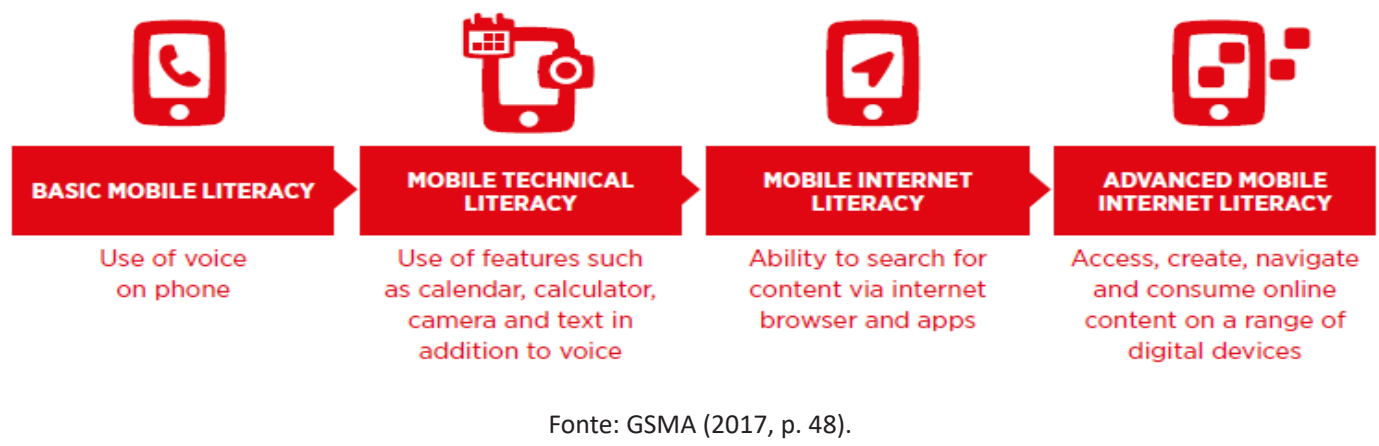

A partir destes estudos, pode-se constatar que o caminho para diminuir a desigualdade digital é longo, ou seja, é um processo que deve prever capacitação e assegurar que o jovem tenha, no âmbito da educação, inteligência e capacidade técnica de atuar na rede, criar e produzir conteúdo e significados (SILVEIRA, 2002). E, ao pesquisar sobre o jovem, educação e o mercado de trabalho torna-se importante refletir sobre a relação entre teoria e prática, consistindo como parte do desenvolvimento das competências afetivas vinculadas à capacidade para lidar com a incerteza, com a dinamicidade e com o estresse, de forma comprometida com uma nova concepção de homem e de sociedade (KUENZER, 2004).

Diversos fatores contribuem para a inclusão e exclusão no mercado trabalho e, para tanto, podem ser considerados aqueles que são originados a partir da própria diversidade humana que, em muitos casos, a própria inclusão traz consigo julgamentos e comportamentos (pessoais ou do grupo) que favorecem a exclusão em dado momento, por diversas circunstâncias, que são vinculadas à competitividade em prol da manutenção das condições materiais da existência (ANDRÉ, 2013).

A constante transformação do mundo do trabalho cria uma série de incertezas em relação ao futuro. Dessa forma, o aumento do desemprego cria em diversas partes do mundo possíveis novas práticas de enfrentamento, fazendo com que trabalhadores de diferentes segmentos continuem a buscar meios de geração de renda. Isso tende a provocar um impacto significativo em seus modos de vida e, em função de que surgem novas necessidades, sobretudo, por questões relacionadas ao emprego contemporâneo, ou mesmo a falta dele, nos mais diversos setores da economia (VIANA, 2019).

Na pesquisa realizada para este artigo, $73 \%$ dos jovens respondentes citaram que não se acham preparados(as) para as demandas e competências digitais do mundo do trabalho. Na Figura 5 está ilustrado, através da ferramenta de nuvem de palavras, os termos mais mencionados pelos pesquisados. 


\section{Figura 5 - Nuvem de palavras com as respostas para "Você se acha preparado(a)} para as demandas e competências digitais do mundo do trabalho? Por quê?"

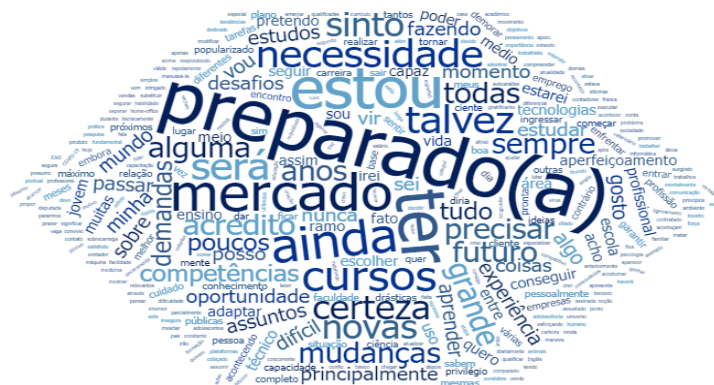

Fonte: Elaborado pelos autores.

Os jovens destacaram as palavras: preparado(a), mercado, cursos e necessidade. Nas respostas pode-se observar que alguns jovens respondentes citam a necessidade de estar sempre estudando:

Jovem: 'Eu pretendo fazer algum curso para me ingressar nos assuntos da atualidade.'

Jovem: 'Tenho em mente que durante toda minha carreira vou precisar ficar realizando cursos entre outras coisas para me atualizar.'

Jovem: 'É preciso adquirir meios de experiências através da comunicação, estudos.'

Mas, eles têm consciência que mesmo com cursos a inserção é difícil:

Jovem: 'Com os cursos que preparam pra essa nova etapa, não será tão difícil se adaptar em um novo meio, mas sempre haverá controvérsias, tais como a falta de oportunidade de tantos outros jovens, e talvez mais necessitados que eu, isso me deixa intrigado, pois nem todos terão as mesmas oportunidades que eu tive, e estou tendo.'

Jovem: 'É preciso agarrar com força toda e qualquer oportunidade de aperfeiçoamento acadêmico ou profissional, pois tudo será válido e talvez um único ponto poderá significar a diferença entre ser ou não contratado para uma vaga muito disputada.'

Jovem: 'Preciso terminar meu curso e fazer um estágio para me profissionalizar na carreira que quero seguir.'

Ala-Mutka (2011) destaca que o indivíduo que não possua um nível suficiente de competências digitais, além de usar de forma inadequada as tecnologias, poderá ser excluído de diferentes atividades sociais e perder importantes oportunidades. Também foram citadas pelos jovens as mudanças significativas no mercado de trabalho neste momento de quarentena, como por exemplo na resposta a seguir:

Jovem: 'O mercado de trabalho já está tendo várias demandas diferentes em grande parte voltadas ao ramo da tecnologia, necessitando de pessoas com novas competências para assumir lugares de grande importância. Teremos novas tendências de trabalhos nos próximos anos, talvez com toda essa crise que está acontecendo no mundo por conta do vírus covid-19, o home office se torne algo mais popularizado, vindo ser mais usado para profissões que a pessoa não necessariamente precise sair de casa para executar.' 
Assim como, o impacto da covid-19 na educação:

Jovem: 'A educação também poderá passar por uma mudança drástica, talvez vejamos o uso de aulas EAD se popularizando para além de algumas faculdades ou cursos específicos. Podem começar a aparecer no ensino médio e talvez até mesmo no fundamental, ou seja, os professores teriam que se adaptar a esta nova demanda do mercado de trabalho.'

Mas, independentemente da pandemia, existem questões sobre a educação pública que assusta alguns jovens:

Jovem: 'Embora eu sempre tenha me dedicado aos estudos, tive formação em uma escola pública não tão bem preparada para ajudar os adolescentes na vida pós colegial, e mesmo sabendo que já sou privilegiada por poder estar fazendo um curso técnico, não me sinto nem de longe pronta pra quando tiver que entrar de fato no mercado de trabalho.'

Jovem: 'Estudei minha vida toda em escolas públicas, com um péssimo ensino básico, fiz poucos cursos que, por mais que estes ainda me garantam um certo lugar no mercado de trabalho, ainda são poucos comparado ao que será requisitado para conseguir um bom emprego.'

Ressalta-se que não se pode negar que, conforme Migliari, Santa Cruz e Sanches (2019), educar não está limitado às salas de aula, mas se expande para todo o contexto urbano e social, pela importância da educação como um processo de formação da sociabilidade. Contudo, em outras palavras, as preocupações sobre a educação pública sinalizam que os jovens veem que um bom currículo escolar pode ser um diferencial em sua carreira, o que remete às considerações feitas nos estudos de Bauman (2013, p. 73-74):

há um número enorme de jovens fisicamente aptos, em idade escolar, que são desabilitados em suas tentativas de atingir os padrões estabelecidos pelo mercado de trabalho em função da circunstância de terem nascido e crescido em famílias com rendimentos abaixo da média ou em bairros pobres e esquecidos.

Já Kuenzer (2007, p. 1170) explica que mesmo com a inclusão a pessoa ainda pode estar excluída, a autora exemplifica sob o aspecto da distribuição desigual e diferenciada de educação:

A estratégia por meio da qual o conhecimento é disponibilizado/negado, segundo as necessidades desiguais e diferenciadas dos processos de trabalho integrados, é o que temos chamado de inclusão excludente na ponta da escola. Ao invés da explícita negação das oportunidades de acesso à educação continuada e de qualidade, há uma aparente disponibilização das oportunidades educacionais, por meio de múltiplas modalidades e diferentes naturezas, que se caracterizam por seu caráter desigual e, na maioria das vezes, meramente certificatório, que não asseguram domínio de conhecimentos necessários ao desenvolvimento de competências cognitivas complexas vinculadas à autonomia intelectual, ética e estética.

Outro ponto importante, conforme ilustrado na Figura 5, foram as expressões: "talvez", "novas", "sempre", "certeza", citadas pelos jovens respondentes. A seguir alguns exemplos:

Jovem: 'Quero estar em contato com esses desafios, propor ideias e colocá-las em prática. Talvez seja por isso que encontro certa dificuldade para decidir em que área atuar.'

Jovem: 'Preparados nós nunca vamos estar cem porcento, mas tenho certeza que eu sempre vou lutar para me modificar.'

Jovem: 'Bom, me acho sim preparado para as novas demandas, pois, estou em contínuo movimento.' 
A partir destas percepções de incertezas e certezas descritas pelos jovens pesquisados, pode-se afirmar que ainda se remetem as mesmas características citadas há três décadas por Pais (1990) que aborda dois eixos inerentes aos estudos de juventudes: unidade e diversidade, que também são descritas por Bauman (2013) sobre a sociedade líquida, por Schmidt (2007) sobre a juventude líquida, e especificamente no caso do trabalho, por Feixa, Strecker e Ballesté (2020, p. 209-210, tradução nossa):

No caso do trabalho, os jovens experimentaram tudo de melhor - mas também o pior [...]. Por um lado, possui aspectos negativos que implicam custos: instabilidade do emprego, precariedade, descontinuidade, dificuldades na realização de projetos a médio e longo prazo, destruição de postos de trabalho, etc. Por outro lado, também tem aspectos positivos que abrem oportunidades: relações de trabalho mais horizontais e criativas, horários flexíveis, valorização da inovação, quebra de hierarquias obsoletas, necessidade de reciclagem constante (aprendizagem ao longo da vida), etc ${ }^{5}$.

Contexto que se revela, por exemplo, na preocupação em estar sempre atualizado de alguns jovens, conforme alguns exemplos a seguir:

Jovem: 'Por mais que eu acompanhe as novas tecnologias e tenha convívio com os avanços tecnológicos eu precisaria me aperfeiçoar e me atualizar para suprir as necessidades do mercado.' Jovem: 'Reconheço que devo sempre ter capacitação para trabalhar com tecnologias, afinal esse é o nosso futuro.'

Contudo, cabe ressaltar que, mesmo nos $23 \%$ que responderam que estão preparados, há a preocupação com as mudanças, alguns exemplos:

Jovem: 'Acredito que tenho capacidade de aprender ainda mais sobre as tecnologias utilizadas neste meio, e usar do meu privilégio de ter facilidade para entender a maneira de manuseá-la.'

Jovem: 'Sei que será um pouco difícil ingressar em um ramo tão incerto se serei capaz de fazer todas as tarefas, mas sei que serei capaz de enfrentá-las e fazê-las.'

Jovem: 'O meu trabalho exige bastante que eu me atualize nas novas demandas tecnológicas, até mesmo porque muitas coisas que fizemos são feitas somente pela internet. Muitas vezes algumas coisas são novas pra mim, procuro sempre entender e aprender, até mesmo porque se não fizermos isso ficaremos para trás, pois a tecnologia vem se avançando cada vez mais.'

Ou seja, pode-se perceber que para as juventudes a alfabetização digital básica pode ser o mediador entre sua inclusão ou exclusão social. Van Dijck (2013) destaca que na "cultura da conectividade" permanecer on-line transformou-se numa necessidade social e profissional, principalmente para os jovens. Dessa forma, não é exagero mencionar que atualmente é impossível existir práticas que visam à inclusão, ao reconhecimento e à legitimação da diversidade, sem incluir políticas que contemplem as juventudes. Conforme Reig e Vílchez (2013, p. 13, tradução nossa, grifo do autor) o smartphone tem significado importante neste processo, pois

Vivemos cada vez mais, não com esse dispositivo, mas nesse dispositivo. Através dele gerenciamos uma parte crescente de nossa vida como indivíduos, cidadãos e trabalhadores. [...]

5 No original: “En el caso del trabajo, los jóvenes experimentaban todo lo mejor - pero también lo peor [...]. Por un lado, tiene aspectos negativos que implican costes: inestabilidad en el trabajo, precariedad, discontinuidad, dificultades en hacer proyectos a medio y largo plazo, destrucción de puestos de trabajo, etc. Por otra parte, tiene también aspectos positivos que abren oportunidades: relaciones laborales más horizontales y creativas, flexibilidad horaria, valoración de la innovación, ruptura de jerarquías obsoletas, necesidad de reciclaje constante (lifelong learning), etc." 
Os mais jovens estão crescendo e estão se formando como pessoa, cidadãos e futuros trabalhadores na onipresença destes dispositivos ${ }^{6}$.

Neste cenário, retomamos os estudos de Van Dijck (2013) que destaca que muitas atividades informais diárias se tornaram atividades formais mediadas por aplicativos e serviços on-line. Assim, ao mesmo tempo que as atividades cotidianas realizadas com o uso dos telefones celulares apresentam características globais, como por exemplo efetuar e receber chamadas telefônicas, ouvir músicas, jogar, assistir a vídeos, acessar páginas ou sites, tirar fotos, usar mapas, compartilhar fotos, vídeos ou textos, acessar redes sociais, baixar aplicativos, entre outros, segundo o Comitê Gestor da Internet no Brasil (CGI.BR, 2017). Todavia, não se pode falar de experiências uniformes ou estandardizadas, pois os comportamentos e hábitos das juventudes são muito diversos (REGUILLO CRUZ, 2010; ROCHA; PEREIRA, 2009; WINOCUR, 2007).

Como citado na introdução deste artigo, 4 bilhões de pessoas ainda estão desconectadas. Neste contexto, a exclusão digital é um dos pontos latentes, principalmente quando analisado as atividades realizadas no celular por classe social no Brasil. Como ilustra o Gráfico em 2016, na classe A todas as atividades realizadas com um celular estão acima de 78\%, com exceção de jogar (43\%). Já nas classes D/E, "fez e recebeu chamadas telefônicas" apresenta 91\%, "ouvir música” com $57 \%$, "tirar fotos" $55 \%$ e todas as demais estão abaixo de $50 \%$.

\section{Gráfico 1 - Proporção de usuários de telefone celular, por ativi-} dades realizadas no celular, por classe social, Brasil, 2016

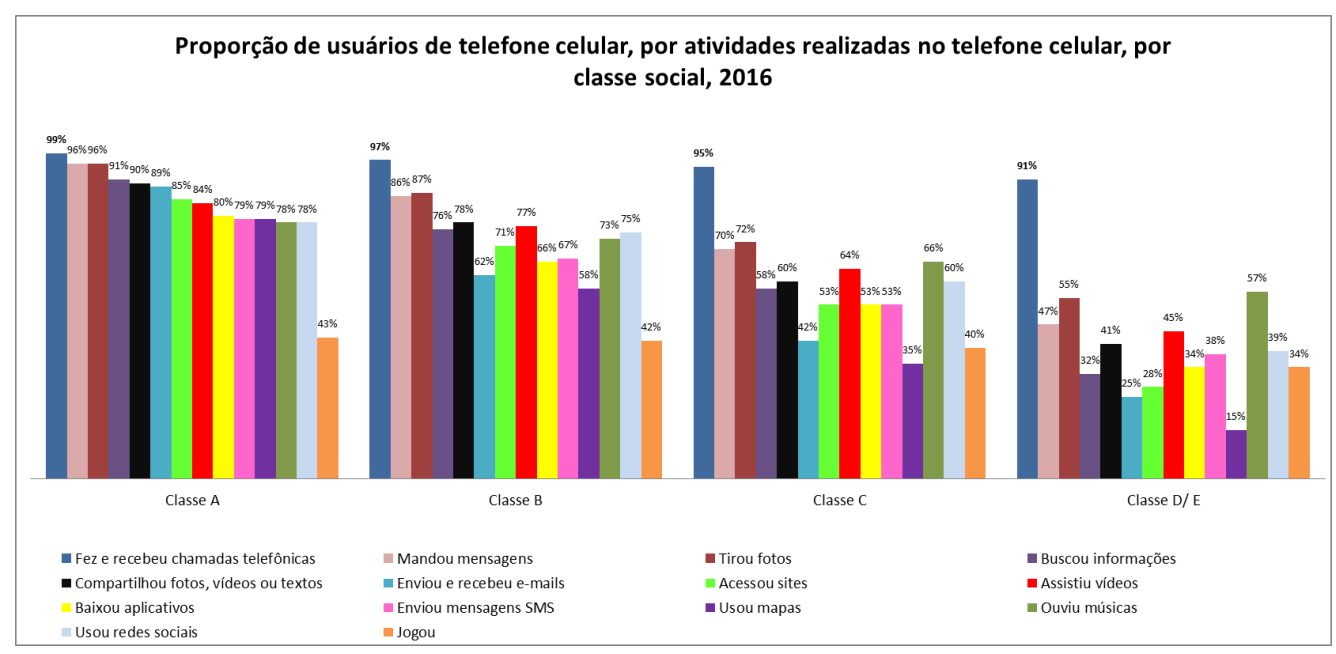

Fonte: Elaborado pelos autores

Além das atividades citadas no Gráfico 1, somente 17\% dos usuários de internet da classe D compraram produtos e serviços pela internet e $9 \%$ divulgaram ou venderam produtos ou serviços pela internet nos últimos doze meses (CGI.BR, 2017). O principal motivo apresentado por $61 \%$ dos respondentes foi "por falta de confiança no produto que vai receber". Já na classe A, nos últimos doze meses, tem-se $81 \%$ das pessoas que compraram produtos e serviços pela internet e $32 \%$ divulgaram ou venderam produtos ou serviços, sendo o principal motivo "preferir comprar pessoalmente, gostar de ver o produto", descrito por 67\% (CGI.BR, 2017).

Portanto, não é errado mencionar que a exclusão digital se consolida como a barreira para a transição da escola para o mercado de trabalho. O acesso ao digital não é apenas uma questão de acesso à tecnologia, mas de hábitos culturais, que transcende as desigualdades de classe e precisa ter esforços de organismos públicos e privados, bem como de toda a sociedade.

6 No original: "Vivimos cada vez más, no con ese aparato, sino en ese aparato. A través de él gestionamos una parte creciente de nuestra vida como individuos, ciudadanos y trabajadores. [...] Los más jóvenes están creciendo y se están formando como personas, ciudadanos y futuros trabajadores en la omnipresencia de estos dispositivos." 


\section{Conclusão}

Este artigo apresentou alguns apontamentos sobre a inclusão digital, com foco em refletir sobre a percepção dos jovens em relação às perspectivas na transição da escola para o trabalho no que se refere a estar preparado(a) para as demandas e competências digitais do mundo do trabalho, a partir da pesquisa realizada on-line no mês de maio de 2020 com jovens de camada média na cidade de Novo Hamburgo (RS).

Os resultados indicam que os respondentes, possuem uma série de receios em relação ao seu futuro profissional, e que embora seja um fato comum em suas faixas etárias, no grupo estudado, há uma profunda preocupação com a necessidade de "estar preparado" para o mercado de trabalho, indicador citado constantemente ao longo da pesquisa. Ao mesmo tempo, parte dos respondentes mencionam a importância de permanecer "sempre estudando", o que demonstra que os jovens buscam observar o contexto contemporâneo relacionado ao mercado de trabalho, uma pauta presente nos desafios e nos medos sobre o seu futuro.

A pergunta de pesquisa foi: Os jovens acreditam estar preparados(as) para as demandas e competências digitais do mundo do trabalho? Considera-se que a questão norteadora da pesquisa foi respondida, pois através da análise do levantamento efetuado, percebeu-se que os jovens não se consideram plenamente preparados para o mercado de trabalho. Como citado, alguns respondentes entendem a importância do aprendizado contínuo, principalmente em relação ao uso de tecnologias.

Os respondentes entendem que suas futuras profissões perpassam por atividades que poderão ser feitas somente pela internet, e que o aperfeiçoamento para suprir "as necessidades do mercado" necessitam de uma educação escolar atualizada aos desafios do século XXI. Considera-se aqui, que parte das respostas nos participantes, também podem ser influenciadas pelo contexto das informações da pandemia do covid-19, pois no período da pesquisa (maio de 2020), atividades profissionais com o enfoque no home office eram constantemente discutidas, em razão da necessidade de promover o distanciamento social.

Por fim, observa-se que perceber o processo de inclusão digital das juventudes é uma reflexão perene na sociedade. Embora, muitas vezes acredita-se que o jovem contemporâneo já possui o contato com as novas tecnologias desde a primeira infância e, que isso, de certo modo, o diferenciaria do perfil do jovem de outras décadas, não é uma verdade absoluta. As barreiras à inclusão digital existentes na América Latina e Caribe ainda são altas, ações para diminuir a brecha digital e aumentar alfabetização mobile são cruciais e, trarão benefícios básicos de conectividade a todos os jovens.

Entende-se, também, que os jovens pesquisados percebem as competências tecnológicas como um requisito importante para sua formação profissional atual, mas ainda persiste a dicotomia que busca a relação entre teoria e prática, pois o jovem já compreende que determinadas habilidades, terão relação direta com sua perspectiva de vida profissional, ainda que, a vulnerabilidade que as juventudes enfrentam estão além do desemprego.

Como proposta futura para a continuidade da pesquisa, acredita-se que efetuar um mapeamento de quais são as profissões futuras, que na opinião dos jovens, podem ser identificadas como mais necessárias para adquirir competências tecnológicas é um tema relevante. Pois desse modo, pode-se efetuar uma comparação com as principais tendências relacionadas ao futuro do trabalho. Enfim, acredita-se que as juventudes contemporâneas estão engajadas com a busca pela qualificação para o enfrentamento e os desafios impostos em relação ao trabalho na contemporaneidade. 


\section{Referências}

ABRAMOVAY, Miriam; CASTRO, Mary Garcia. Juventude, Juventudes: o que une e o que separa. Brasília, DF: Editora Unesco, 2006.

ALA-MUTKA, Kirsti. Mapping Digital Competence: Towards a Conceptual Understanding. Seville: JRC/IPTS, 2011. Disponível em: 10.13140/RG.2.2.18046.00322. Acesso em: 5 jan. 2021.

ANDRÉ. O sofrimento no trabalho: Artigo de Christophe Dejours. Instituto Humanitas Unisinos, São Leopoldo, 10 maio 2013. Disponível em: http://www.ihu.unisinos.br/noticias/520004-o-sofrimento-no-trabalho-artigo-de-christophe-dejours. Acesso em: 10 jan. 2021.

BARDIN, Laurence. Análise de Conteúdo. Lisboa: Edições 70, 2004.

BAUMAN, Zygmunt. Sobre educação e juventude: conversas com Riccardo Mazzeo. Rio de Janeiro: Zahar, 2013.

BAUMAN, Zygmunt; RAUD, Rein. A individualidade numa época de incertezas. Rio de Janeiro: Zahar, 2018.

BRASIL. Lei $n .^{\circ} 10.741$, de $1^{\circ}$ de outubro de 2003. Dispõe sobre o Estatuto do Idoso e dá outras providências. Brasília, DF: Presidência da República, [2003].

BRASIL. Lei $n .^{\circ}$ 12.852, de 5 de agosto de 2013. Inclui o Estatuto da Juventude e dispõe sobre os direitos dos jovens [...]. Brasília, DF: Presidência da República, [2013]. Disponível em: http://www.planalto.gov.br/ccivil_03/_ato2011-2014/2013/ lei/l12852.htm. Acesso em: 10 jan. 2021.

CASTELLS, Manuel et al. Comunicación móvil y sociedad una perspectiva global. Barcelona: Ariel, 2006.

COMITÊ GESTOR DA INTERNET NO BRASIL (CGI.br). TIC Domicílios 2016: Pesquisa sobre o Uso das Tecnologias de Informação e Comunicação no Brasil. São Paulo: CGI.br, 2017. Disponível em: http://data.cetic.br/cetic/explore?idPesquisa=TIC_DOM. Acesso em: 8 jan. 2021.

COMISSÃO DAS COMUNIDADES EUROPEIAS (COM). Recomendação do Parlamento Europeu e do Conselho: sobre as competências-chave para a aprendizagem ao longo da vida. Bruxelas: Comissão das Comunidades Europeias, 2005. Disponível em: http://www.europarl.europa.eu/meetdocs/2004_2009/documents/com/com_com(2005)0548_/ com_com(2005)0548_pt.pdf. Acesso em: 5 jan. 2021.

FEIXA, Carles. A construção histórica da juventude. In: CACCIA-BAVA, Augusto et al. Jovens na América Latina. São Paulo: Escrituras Editora, 2004. p. 257-327.

FEIXA, Carles. De jóvenes, bandas y tribus. Barcelona: Ariel, 1999.

FEIXA, Carles; STRECKER, Tanja; BALLESTÉ, Eduard. El sentido del trabajo en las personas jóvenes: diversidades y cambios. Gaceta Sindical: reflexión y debate, Logroño, n. 34, p. 203-220, 2020.

BENCINI, Roberta; GENTILE, Paola. Construindo competências: Entrevista com Philippe Perrenoud, Universidade de Genebra. Nova Escola, São Paulo, p. 19-31, set. 2000. Disponível em: http://www.unige.ch/fapse/SSE/teachers/ perrenoud/php_main/php_2000/2000_31.html. Acesso em: 5 jan. 2021.

FREITAS, Ernani Cesar de; PRODANOV, Cleber Cristiano. Metodologia do Trabalho Científico: Métodos e Técnicas da Pesquisa e do Trabalho Acadêmico. 2. ed. Novo Hamburgo: Editora Feevale, 2013.

GARBIN, Elisabete Maria et al. Identidades Juvenis em Territórios Culturais Contemporâneos. UNIrevista, São Leopoldo, v. 1, n. 2, p. 14, abr. 2006.

GLOBAL SYSTEM FOR MOBILE COMMUNICATIONS ASSOCIATION LATIN AMERICA (GSMA/LATAM). EConomía Móvil 2017: América Latina y Caribe. 2017. Disponível em: https://www.gsma.com/latinamerica/es/resources/ mobile-economy-latin-america-caribbean-2017/. Acesso em: 10 jan. 2021.

GLOBAL SYSTEM FOR MOBILE COMMUNICATIONS ASSOCIATION LATIN AMERICA (GSMA/LATAM). The Mobile Economy. 2021. Homepage. Disponível em: https://www.gsma.com/mobileeconomy/latam/. Acesso em: 10 jan. 2021.

GLOBAL SYSTEM FOR MOBILE COMMUNICATIONS ASSOCIATION LATIN AMERICA (GSMA/LATAM). The Mobile Economy Latin America 2020. London: GSM Association, 2020.

KUENZER, Acacia Zeneida. Da dualidade assumida à dualidade negada: o discurso da flexibilização justifica a inclusão excludente. Educação \& Sociedade, Campinas, v. 28, n. 100, p. 1153-1178, out. 2007. Disponível em: http://www.scielo. br/pdf/es/v28n100/a2428100.pdf. Acesso em: 5 jan. 2021. 
“Com uma autoanálise, rápida e franca, eu diria que não estou preparado para estas novas competências"...

KUENZER, Acacia Zeneida. Competência como Práxis: os dilemas da relação entre teoria e prática na educação dos trabalhadores. Boletim Técnico do SENAC, Rio de Janeiro, v. 30, n. 3, p. 81-93, set./dez. 2004. Disponível em: http://servicos.educacao.rs.gov.br/dados/seminariointernacional/acacia_kuenzer_competencia_praxis.pdf. Acesso em: 5 jan. 2021.

MIGLIARI, Mirela de Menezes; SANCHES, Sandra; SANTA CRUZ, Lucia. O Investimento na Inteligência Humana é a Oportunidade de Amanhã: Entrevista com o filósofo Gilles Lipovetsky. Contracampo, Niterói, v. 37, n. 3, p. 191-205, mar. 2019 .

MINISTÉRIO DA SAÚDE. Sobre a doença: O que é COVID-19. 2021. Homepage. Disponível em: https://coronavirus. saude.gov.br/sobre-a-doenca. Acesso em: 10 jan. 2021.

ORGANIZAÇÃO DAS NAÇÕES UNIDAS (ONU). Promotion and protection of all human rights, civil, political, economic, social and cultural rights, including the right to development. Geneva: ONU, 2011. Disponível em: http://www2. ohchr.org/english/bodies/hrcouncil/docs/17session/A.HRC.17.27_en.pdf. Acesso em: 15 dez. 2020.

PAIS, José Machado. A construção sociológica da juventude: alguns contributos. Análise Social, Lisboa, v. 25, n. 105/106, p. 139-165, 1990.

REGUILLO CRUZ, Rossana. La condición juvenil en el México contemporâneo: Biografías, incertidumbres y lugares. In: REGUILLO CRUZ, Rossana (coord.). Los jóvenes en México. México: FCE/CONACULTA, 2010. p. 395-426.

REIG, Dolors; VÍLCHEZ, Luis Fernando. Los jóvenes en la era de la hiperconectividad: tendencias, claves y miradas. Madrid: Fundación Telefónica y Fundación Encuentro, 2013.

PEREIRA, Cláudia; ROCHA, Everardo. Juventude e Consumo: um estudo sobre a comunicação na cultura contemporânea. Rio de Janeiro: Mauad X, 2009.

SARLO, Beatriz. Cenas da vida pós-moderna: intelectuais, arte e vídeo-cultura na Argentina. Rio de Janeiro: Editora UFRJ, 1997.

SCHMIDT, Sarai. Ter Atitude: Juventude Líquida na Pauta, Um estudo sobre mídia e cultura jovem global. In: XVI COMPÓS, 2007, Curitiba. Anais [...]. Curitiba: UTP, 2007. p. 1-17. Grupo de Trabalho Recepção, Usos e Consumo Midiáticos.

SILVEIRA, Sérgio Amadeu da. Inclusão Digital, Software Livre e Globalização Contra-Hegemônica. Software Livre, Brasília, DF, 2002. Disponível em: http://www.softwarelivre.gov.br/artigos/artigo. Acesso em: 5 jan. 2021.

SORJ, Bernardo.brasil@povo.com: a luta contra a desigualdade na Sociedade da Informação. Rio de Janeiro: Jorge Zahar, 2003

TELECO: Portal Teleco, 2020. Homepage. Disponível em: http://www.teleco.com.br. Acesso em: 15 dez. 2020.

ORGANIZAÇÃO DAS NAÇÕES UNIDAS PARA A EDUCAÇÃO, A CIÊNCIA E A CULTURA (UNESCO). Padrões de Competência em TIC para Professores: diretrizes de implementação, versão 1.0. Brasília, DF: Editora Unesco, 2009. Disponível em: http://unesdoc.unesco.org/images/0015/001562/156209por.pdf. Acesso em: 5 jan. 2021.

VAN DIJCK, Jose. The Culture of Connectivity: a critical history of social media. New York: Oxford University Press, 2013.

VELHO, Gilberto. Individualismo e Cultura: notas para uma antropologia das sociedades contemporâneas. Rio de Janeiro: Jorge Zahar, 1988.

VELHO, Gilberto. Juventudes, projetos e trajetórias na sociedade contemporânea. In: ALMEIDA, Maria Isabel Mendes de; EUGENIO, Fernanda. Culturas jovens: novos mapas do afeto. Rio de Janeiro: Jorge Zahar, 2006. p. 192-200.

VIANA, André Luciano. As contradições do movimento Slow e a ressignificação do trabalho na contemporaneidade: uma reinvenção de mercados? 2019. 210 f. Tese (Doutorado em Diversidade Cultural e Inclusão Social) - Feevale, Novo Hamburgo, 2019. Disponível em: https://biblioteca.feevale.br/Vinculo2/000018/000018de.pdf. Acesso em: 10 jan. 2021.

WINOCUR, Rosalía. Apropiación de Internet y la computadora en sectores populares urbanos. Otras Voces, México, v. 19, p. 191-216, 2007.

Data de submissão: 22/01/2021

Data de aceite: $25 / 01 / 2021$ 